Int. J. Electrochem. Sci., 15 (2020) $6981-6990$

International Journal of

ELECTROCHEMICAL

SCIENCE

$\underline{\text { www.electrochemsci.org }}$

\title{
An Efficient Electrocatalyst for the Nano-Level Detection of Neurotransmitter (Dopamine) in Biologic Matrices based on Samarium (III) Oxide Nanoparticles; An Electrochemical Approaches
}

Elayappan Tamilalagan ${ }^{1,} \uparrow$, Tse-Wei Chen ${ }^{2,3,} \dagger$, Shen-Ming Chen ${ }^{1, *}$, Muthumariappan Akilarasan ${ }^{1}$, Y- $^{-}$ Chen Huang ${ }^{1}$, Syang-Peng Rwei $i^{3,4}$

${ }^{1}$ Department of Chemical Engineering and Biotechnology, National Taipei University of Technology, Taipei, Taiwan 106 (ROC).

${ }^{2}$ Department of Materials, Imperial College London, London, SW7 2AZ, United Kingdom

${ }^{3}$ Research and Development Center for Smart Textile Technology, National Taipei University of

Technology, Taiwan

${ }^{4}$ Institute of Organic and Polymeric Materials, National Taipei University of Technology,

"E-mail: smchen78@ms15.hinet.net

$\uparrow$ Authors contributed equally.

doi: $10.20964 / 2020.07 .95$

Received: 1 April 2020 / Accepted: 25 May 2020 / Published: 10 June 2020

Dopamine (DA) play a vital role in brain as a neurotransmitter and its excess secretion can leads to several abnormalities. The important challenge in DA detection was the existence of interference like ascorbic acid and uric acid in blood. Therefore, it is important to improve the selective and sensitive detection of DA in biological samples. Herein, we reported the synthesis of samarium oxide $\left(\mathrm{Sm}_{2} \mathrm{O}_{3}\right)$ nanoparticle for the selective detection of DA. The morphological and chemical composition of the as prepared $\mathrm{Sm}_{2} \mathrm{O}_{3}$ NPs was characterized by using FESEM and XRD. In addition, the synthesized $\mathrm{Sm}_{2} \mathrm{O}_{3}$ NPs were modified on the GCE surface, which was subjected for the determination of DA. Moreover, the $\mathrm{Sm}_{2} \mathrm{O}_{3} \mathrm{NPs} / \mathrm{GCE}$ has displayed the wider covering range of 0.01 to $342.9 \mu \mathrm{M}$ with limit of detection up to $2.54 \mathrm{nM}$. The $\mathrm{Sm}_{2} \mathrm{O}_{3} \mathrm{NPs} / \mathrm{GCE}$ were successfully examined with DA spiked human blood serum and urine samples, which shows the appreciable found and recovery values.

Keyword: Samarium oxide; Dopamine sensor; neurotransmitter; biologic matrices; electrochemical method.

\section{$\underline{\text { FULL TEXT }}$}


(C) 2020 The Authors. Published by ESG (www.electrochemsci.org). This article is an open access article distributed under the terms and conditions of the Creative Commons Attribution license (http://creativecommons.org/licenses/by/4.0/). 